\author{
Military Technical College \\ Kobry El-kobbah, \\ Cairo, Egypt
}

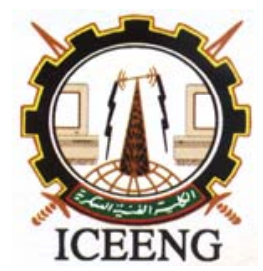

\title{
SHIELDING CHARACTERISTICS OF AN INFINITELY EXTENDED CONDUCTING STRIP-ARRAY EMBEDDED IN MULTILAYERED DIELECTRIC CYLINDRICAL STRUCTURE
}

\author{
Elregaily ${ }^{*}$ H. A., Mohktar ${ }^{*}$ M. M. and Allam * A. M.
}

\begin{abstract}
A plane wave excitation of an infinitely extended conducting strip-array embedded in multilayered dielectric cylinder, as a shielding structure, has been studied. Based on the Green's functions, the integral equation is formulated for describing the current on a conducting strip-array. Using Galerkin's method, the surface currents on the conducting strips are expanded in the form of series weighted Chebyshev polynomials of the first kind and the unknown coefficients are obtained by solving a resultant system of linear equations.

The validity of the formulation and the accuracy of the numerical solution are demonstrated for different array geometries. The numerical results depict the penetrated (near-zone) and the scattered (far-zone) fields for four different array geometries. Some of these results are compared to the simulated results using Zeland Fidelity Workshop (ZFW), and a good agreement was achieved.
\end{abstract}

Key word - Multilayered shielding, TM-polarized plane wave, Galarkin's method, penetrated field, scattered field.

\section{Introduction}

Coupling of electromagnetic energy into electronic devices and systems can cause electrical overstress to their internal circuits. Modern semiconductor integrated circuits are much more vulnerable to damage by overstresses than earlier electronic circuits, which used vacuum tubes and relays. This leads to failure, permanent degradation, or temporary malfunction (upset) of electronic devices and systems. Electromagnetic shielding is a technique that reduces the coupling of undesired radiated electromagnetic energy into equipment, so as to enable it to operate compatibly with its electromagnetic environment.

* Egyptian Armed Forces 
The reduction of coupling can be affected by shielding sensitive components and subsystems with a metallic enclosure, wherever practical. Obviously, the entire system cannot be shielded since antennas will not perform their intended functions when completely enclosed within a metallic shield. Another shielding mean to reduce coupling in a specified frequency band without affecting the characteristics of the antennas includes the shielding by using structures consisting of apertures / patches that acts as a filter to electromagnetic energy at frequencies outside the frequency band of interest for the system.

The plane wave penetration through cylindrical structures consisting of apertures has been investigated during the past years. The penetration of TM electromagnetic wave into a conducting circular cylinder shell with infinitely extended slit using E- Field integral equation (EFIE) has been introduced [1]. The EFIE has been solved numerically for the induced current on the shell using the method of moment, and hence the scattered field has been calculated. This method failed to accurately determine the field inside the cylinder when the slot is so narrow (the magnitude of the field is less than one millionth of the incident field). The pseudo-image method, as mentioned in [2], has been used to accurately solve such an extremely narrow slot problem, provided that the frequency is not close to a resonance frequency of the associated cavity (enclosed by complete cylindrical surface).

An accurate numerical solution to the problem of circular cylindrical shell with a very narrow slot excited by both TM- and TE- polarizations when the frequency is close to a resonance frequency of the associated cavity has been given by Mutz and Harrington [2,3]. The formulation is based on the generalized network formulation for aperture problem [4], that depend on the application of equivalence principle to separate the problem into two regions on each side of the aperture, whose characteristics can be expressed by aperture admittance matrices one for each region. The aperture coupling is the sum of these two independent matrices, with source terms related to the incident magnetic field and the solution is given in terms of method of moments.

Three methods for determining the field which penetrates conducting cylinders containing narrow axially conducting slots for both TE- and TM- polarizations have been introduced by Chalmers and Butler [5,6]. Firstly, is the scatterer method that treats the body as a scatterer and determines the interior field as the sum of the incident field produced by known source and the scattered field produced by the current in the body. Secondly, the short - circuit current method is based upon the field equivalence theorem, which allows one to change the excitation of the structure from the known source or incident field to an equivalent surface current placed on the aperture. The penetrated field can be determined by a procedure similar to that of scatterer method. Thirdly, the equivalent current method employs the equivalence principle to solve the equivalent magnetic currents and determine the field by knowledge of these currents. In all these methods integral equations are derived, that when solved by using method of moments yield currents from which penetrated field can be determined.

On the other hand, another cylindrical structure, consisting of multiple aperture system has been studied by Wen-Yan Yin et al [7]. They investigate the TEz- polarized plane wave penetrating through multilayered cylindrical cavity-backed apertures. The mathematical procedure is based on the direct integral equation technique combined with Galerkin's procedure, that can be solved numerically for the magnetic currents on the surround multiple apertures. More recently, they use the same technique to describe the near - zone field characteristics of $\mathrm{TMz}$ plane wave penetrating through cylindrical multiple apertures coated or covered with lossy or lossless media [8]. 
This work is devoted to the problem of $\mathrm{TMz}$ - polarized plane wave excitation of an infinitely extended conducting strip-array embedded in multilayer dielectric cylindrical structure. Based on the Green's functions, the integral equation is derived for describing the electric current distribution on the conducting strips. By using the Galerkin's procedure and taken into consideration the edge effect of the conducting strips, the surface currents are expanded in the form of series weighted Chebyshev polynomials of the first kind. The effect of the strips geometry on the penetrated (near-zone) and scattered (far-zone) fields is studied. Results are compared to the simulated results using Zeland Fidelity Workshop (ZFW).

\section{Formulation}

Figure 1 shows the cross-section of an infinitely extended conducting strip-array embedded in multilayer dielectric cylindrical structure at, $\rho=R_{3}^{\prime}\left(R_{2} \leq R_{3}^{\prime} \leq R_{3}\right)$. The location of each strip is defined by $\left[\psi_{2 s-1}, \psi_{2 s}\right]$, where $s$ is the strip number $(s=1,2 \ldots)$. The regions $\left(\rho<R_{1}\right)$ and $\left(\rho>R_{3}\right)$ are usually a free space with parameters $\varepsilon_{0}$ and $\mu_{0}$.

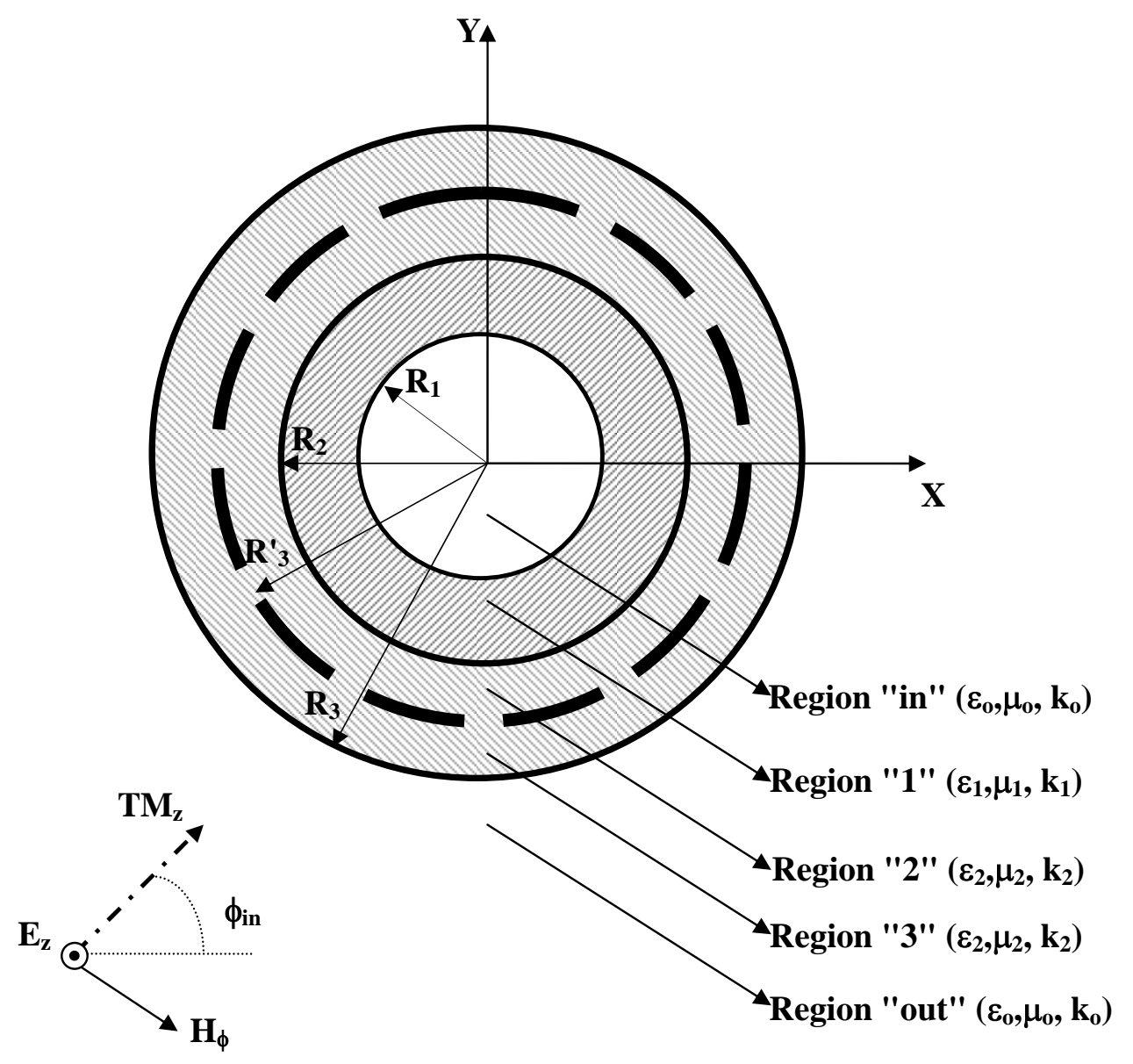

Fig. 1 Cross-section of multilayered infinite dielectric cylinder with conducting strip-array embedded at $\left(\rho=R_{3}^{\prime}\right)$. 
For TMz-polarization, the normally incident electric and magnetic field components [8] is expressed as:

$$
\begin{aligned}
& E_{Z}^{(\text {inc })}=E_{o} \sum_{m=-\infty}^{\infty} j^{-m} J_{m}\left(K_{o} \rho\right) e^{j m\left(\phi-\phi_{i n}\right)} \\
& H_{\phi}^{(\text {inc })}=-\frac{j E_{o}}{\eta_{o}} \sum_{m=-\infty}^{\infty} j^{-m} J_{m}^{\prime}\left(K_{o} \rho\right) e^{j m\left(\phi-\phi_{i n}\right)}
\end{aligned}
$$

where, $K_{\circ}=\omega \sqrt{\mu_{\circ} \varepsilon_{\circ}}, \eta_{\circ}=\sqrt{\mu_{\circ} / \varepsilon_{\circ}}, \phi_{\text {in }}$ is the angle of incidence measured from the $x$-axis, $\mathrm{J}_{\mathrm{m}}\left(\mathrm{K}_{\circ} \rho\right)$ is the cylindrical Bessel function of the first kind of $\mathrm{m}^{\text {th }}$ order and the prim denotes the derivative with respect to $\rho$.

In the absence of the conducting strip array, the excitation field in each region can be described as:

$$
\begin{aligned}
& \rho \geq R_{3} \\
& \mathrm{E}_{\mathrm{Z}}^{(\text {out })}=\mathrm{E}_{\mathrm{o}} \sum_{\mathrm{m}=-\infty}^{\infty} \mathrm{j}^{-\mathrm{m}} \widetilde{\mathrm{A}}_{\mathrm{m}}^{(\text {out })} \mathrm{H}_{\mathrm{m}}^{(2)}\left(\mathrm{K}_{\mathrm{o}} \rho\right) \mathrm{e}^{\mathrm{jm}\left(\phi-\phi_{\text {in }}\right)} \\
& H_{\phi}^{(\text {out })}=-\frac{j E_{o}}{\eta_{o}} \sum_{m=-\infty}^{\infty} j^{-m} \widetilde{A}_{m}^{(\text {out })} H_{m}^{(2)^{\prime}}\left(K_{o} \rho\right) e^{j m\left(\phi-\phi_{\text {in }}\right)} \\
& \mathrm{R}_{2} \leq \rho \leq \mathrm{R}_{3} \\
& \mathrm{E}_{\mathrm{Z}}^{(\mathrm{tr} 2)}=\mathrm{E}_{\mathrm{o}} \sum_{\mathrm{m}=-\infty}^{\infty} \mathrm{j}^{-\mathrm{m}}\left[\widetilde{\mathrm{A}}_{\mathrm{m}}^{(2)} \mathrm{H}_{\mathrm{m}}^{(2)}\left(\mathrm{K}_{2} \rho\right)+\widetilde{\mathrm{B}}_{\mathrm{m}}^{(2)} \mathrm{J}_{\mathrm{m}}\left(\mathrm{K}_{2} \rho\right)\right] \mathrm{e}^{\mathrm{jm}\left(\phi-\phi_{\text {in }}\right)} \\
& \mathrm{H}_{\phi}^{(\operatorname{tr} 2)}=-\frac{j E_{0}}{\eta_{\mathrm{o}}} \sum_{\mathrm{m}=-\infty}^{\infty} \mathrm{j}^{-\mathrm{m}}\left[\widetilde{\mathrm{A}}_{\mathrm{m}}^{(2)} \mathrm{H}_{\mathrm{m}}^{(2)^{\prime}}\left(\mathrm{K}_{2} \rho\right)+\widetilde{\mathrm{B}}_{\mathrm{m}}^{(2)} \mathrm{J}_{\mathrm{m}}^{\prime}\left(\mathrm{K}_{2} \rho\right)\right] \mathrm{e}^{\mathrm{jm}\left(\phi-\phi_{\text {in }}\right)} \\
& \mathrm{R}_{1} \leq \rho \leq \mathrm{R}_{2} \\
& \mathrm{E}_{\mathrm{Z}}^{(\mathrm{tr} 1)}=\mathrm{E}_{\mathrm{o}} \sum_{\mathrm{m}=-\infty}^{\infty} \mathrm{j}^{-\mathrm{m}}\left[\widetilde{\mathrm{A}}_{\mathrm{m}}^{(1)} \mathrm{H}_{\mathrm{m}}^{(2)}\left(\mathrm{K}_{1} \rho\right)+\widetilde{\mathrm{B}}_{\mathrm{m}}^{(1)} \mathrm{J}_{\mathrm{m}}\left(\mathrm{K}_{1} \rho\right)\right] \mathrm{e}^{\mathrm{jm}\left(\phi-\phi_{\text {in }}\right)} \\
& H_{\phi}^{(\operatorname{tr} 1)}=-\frac{j E_{o}}{\eta_{1}} \sum_{m=-\infty}^{\infty} j^{-m}\left[\widetilde{A}_{m}^{(1)} H_{m}^{(2)^{\prime}}\left(K_{1} \rho\right)+\widetilde{B}_{m}^{(1)} J_{m}^{\prime}\left(K_{1} \rho\right)\right] e^{j m\left(\phi-\phi_{\text {in }}\right)} \\
& \rho \leq \mathrm{R}_{1} \\
& E_{Z}^{(\text {in })}=E_{o} \sum_{m=-\infty}^{\infty} j^{-m} \widetilde{B}_{m}^{(\text {in })} J_{m}\left(K_{o} \rho\right) e^{j m\left(\phi-\phi_{\text {in }}\right)} \\
& H_{\phi}^{(i n)}=-\frac{j E_{o}}{\eta_{o}} \sum_{m=-\infty}^{\infty} j^{-m} \widetilde{B}_{m}^{(\text {in })} J_{m}^{\prime}\left(K_{o} \rho\right) e^{j m\left(\phi-\phi_{\text {in }}\right)}
\end{aligned}
$$


where, $\mathrm{K}_{\mathrm{i}}=\omega \sqrt{\mu_{\mathrm{i}} \varepsilon_{\mathrm{i}}}$ and $\mathrm{H}_{\mathrm{m}}^{(2)}\left(\mathrm{K}_{\mathrm{i}} \rho\right)$ is Hankel function of second kind and order $\mathrm{m}(\mathrm{i}=0,1$ and 2), and the unknown coefficients $\widetilde{\mathrm{A}}_{\mathrm{m}}^{(\text {out })}, \widetilde{\mathrm{A}}_{\mathrm{m}}^{(1)}, \widetilde{\mathrm{B}}_{\mathrm{m}}^{(1)}, \widetilde{\mathrm{A}}_{\mathrm{m}}^{(2)}, \widetilde{\mathrm{B}}_{\mathrm{m}}^{(2)}$ and $\widetilde{\mathrm{B}}_{\mathrm{m}}^{(\mathrm{in})}$ are all determined by applying the boundary conditions for tangential components of the electric and magnetic fields at $\rho=R_{1}, R_{2}$ and $R_{3}$ [see appendix $A$ ].

For uniform conducting strip-array in $\hat{\phi}$, embedded at $\rho=\mathrm{R}_{3}^{\prime}$. The scattered fields in the five regions due to the induced surface current Jz on the conductor can be expressed as,

$$
\begin{aligned}
& \mathrm{E}_{\mathrm{Zs}}(\rho, \phi)=\sum_{\mathrm{m}=-\infty}^{\infty}\left[\widetilde{\mathrm{A}}_{\mathrm{TMm}}^{(v)} \mathrm{J}_{\mathrm{m}}\left(\mathrm{K}_{\mathrm{i}} \rho\right)+\widetilde{\mathrm{B}}_{\mathrm{TMm}}^{(v)} \mathrm{H}_{\mathrm{m}}^{(2)}\left(\mathrm{K}_{\mathrm{i}} \rho\right)\right] \mathrm{e}^{\mathrm{jm} \phi} \\
& \mathrm{H}_{\phi s}(\rho, \phi)=\frac{j \omega \varepsilon_{v}}{\mathrm{~K}_{\mathrm{i}}} \sum_{\mathrm{m}=-\infty}^{\infty}\left[\widetilde{\mathrm{A}}_{\mathrm{TMm}}^{(v)} \mathrm{J}_{\mathrm{m}}^{\prime}\left(\mathrm{K}_{\mathrm{i}} \rho\right)+\widetilde{\mathrm{B}}_{\mathrm{TMm}}^{(v)} \mathrm{H}_{\mathrm{m}}^{(2)^{\prime}}\left(\mathrm{K}_{\mathrm{i}} \rho\right)\right] \mathrm{e}^{\mathrm{jm} \phi}
\end{aligned}
$$

$$
\text { where, } \quad v=\left\{\begin{array}{lr}
\text { in } & \rho \leq \mathrm{R}_{1} \\
1 & \mathrm{R}_{1} \leq \rho \leq \mathrm{R}_{2} \\
2 & \mathrm{R}_{2} \leq \rho \leq \mathrm{R}_{3}^{\prime} \\
3 & \mathrm{R}_{3}^{\prime} \leq \rho \leq \mathrm{R}_{3} \\
\text { out } & \rho \geq \mathrm{R}_{3}, \text { and } \widetilde{\mathrm{B}}_{\mathrm{TM}}^{(\text {in) }}
\end{array}=\widetilde{\mathrm{A}}_{\mathrm{TM}_{\mathrm{m}}}^{\text {(out) }}=0\right.
$$

The continuity of the electric and magnetic fields on the inner and outer surfaces of the structure requires that:

$$
\begin{aligned}
& \mathrm{E}_{\mathrm{zs}}^{(1)}=\mathrm{E}_{\mathrm{zs}}^{(\mathrm{in})}, \mathrm{H}_{\phi \mathrm{s}}^{(1)}=\mathrm{H}_{\phi \mathrm{s}}^{(\mathrm{in})} \quad\left(\rho=\mathrm{R}_{1}\right) ; \quad \mathrm{E}_{\mathrm{zs}}^{(2)}=\mathrm{E}_{\mathrm{zs}}^{(1)}, \mathrm{H}_{\phi \mathrm{s}}^{(2)}=\mathrm{H}_{\phi \mathrm{s}}^{(1)} \quad\left(\rho=\mathrm{R}_{2}\right) \\
& \mathrm{E}_{\mathrm{zs}}^{(3)}=\mathrm{E}_{\mathrm{zs}}^{(2)}, \mathrm{H}_{\phi \mathrm{s}}^{(3)}-\mathrm{H}_{\phi \mathrm{s}}^{(2)}=\mathrm{J}_{\mathrm{z}} \quad\left(\rho=\mathrm{R}_{3}^{\prime}\right) ; \quad \mathrm{E}_{\mathrm{zs}}^{(\text {out })}=\mathrm{E}_{\mathrm{zs}}^{(3)}, \mathrm{H}_{\phi \mathrm{s}}^{(\text {out })}=\mathrm{H}_{\phi \mathrm{s}}^{(3)} \quad\left(\rho=\mathrm{R}_{3}\right)
\end{aligned}
$$

Applying the above boundary conditions, the unknown coefficients $\widetilde{\mathrm{A}}_{\mathrm{TM}}^{(v)}$ and $\widetilde{\mathrm{B}}_{\mathrm{TM}}^{(v)}$ can be determined [see appendix B]. Substituting by these coefficients in eqn. (6), the scattered fields in the five regions can be expressed as,

$$
\mathrm{E}_{\mathrm{zs}}^{(v)}=\sum_{\mathrm{m}=-\infty}^{\infty} \mathrm{G}_{\mathrm{zm}}^{(v)} \widetilde{\mathrm{J}}_{\mathrm{zm}} \mathrm{e}^{\mathrm{jm} \phi}
$$

where, $\widetilde{J}_{z m}=\frac{1}{T_{\phi}} \int_{0}^{T_{\phi}} J_{z} e^{-j m \phi^{\prime}} d \phi^{\prime} \ldots$. is the $\mathrm{m}^{\underline{\text { th }}}$. coefficient of the Fourier expansion of the induced current on the conducting strips, $T_{\phi}=2 \pi / \mathrm{P}, \mathrm{P}$ is the number of the metallic strips and $G_{\mathrm{zm}}^{(v)}$ is the Green's functions in different regions, which are determined as: 
region $\left(\rho \leq \mathrm{R}_{1}\right)$

$\mathrm{G}_{\mathrm{zm}}^{(\mathrm{in})}=\left(\frac{\mathrm{K}_{2}}{\mathrm{j} \omega \varepsilon_{2}}\right) \mathrm{V}_{8} \mathrm{~V}_{7} \mathrm{~J}_{\mathrm{m}}\left(\mathrm{K}_{\mathrm{o}} \rho\right)$

region $\left(R_{1} \leq \rho \leq R_{2}\right)$ :

$\mathrm{G}_{\mathrm{zm}}^{(1)}=\left(\frac{\mathrm{K}_{2}}{\mathrm{j} \omega \varepsilon_{2}}\right) \mathrm{V}_{8} \mathrm{~V}_{7}\left[\mathrm{~V}_{1} \mathrm{~J}_{\mathrm{m}}\left(\mathrm{K}_{1} \rho\right)+\mathrm{V}_{2} \mathrm{H}_{\mathrm{m}}^{(2)}\left(\mathrm{K}_{1} \rho\right)\right]$

region $\left(R_{2} \leq \rho \leq R_{3}^{\prime}\right)$ :

$G_{\mathrm{zm}}^{(2)}=\left(\frac{\mathrm{K}_{2}}{j \omega \varepsilon_{2}}\right) \mathrm{V}_{8} \mathrm{~V}_{7}\left[\mathrm{~V}_{5} \mathrm{~J}_{\mathrm{m}}\left(\mathrm{K}_{2} \rho\right)+\mathrm{V}_{6} \mathrm{H}_{\mathrm{m}}^{(2)}\left(\mathrm{K}_{2} \rho\right)\right]$

region $\left(R_{3}^{\prime} \leq \rho \leq R_{3}\right)$ :

$\mathrm{G}_{\mathrm{zm}}^{(3)}=\left(\frac{\mathrm{K}_{2}}{\mathrm{j} \omega \varepsilon_{2}}\right) \mathrm{V}_{7}\left[\mathrm{~V}_{3} \mathrm{~J}_{\mathrm{m}}\left(\mathrm{K}_{2} \rho\right)+\mathrm{V}_{4} \mathrm{H}_{\mathrm{m}}^{(2)}\left(\mathrm{K}_{2} \rho\right)\right]$

region $\left(\rho \geq R_{3}\right)$ :

$\mathrm{G}_{\mathrm{zm}}^{\text {(out) }}=\left(\frac{\mathrm{K}_{2}}{\mathrm{j} \omega \varepsilon_{2}}\right) \mathrm{V}_{7} \mathrm{H}_{\mathrm{m}}^{(2)}\left(\mathrm{K}_{\mathrm{o}} \rho\right)$

where, $\mathrm{V}_{1}, \mathrm{~V}_{2}, \mathrm{~V}_{3}, \mathrm{~V}_{4}, \mathrm{~V}_{5}, \mathrm{~V}_{6}, \mathrm{~V}_{7}$ and $\mathrm{V}_{8}$ are given in appendix $(\mathrm{C})$.

Boundary conditions on the surface of the conductor at $\rho=R_{3}^{\prime}$ can be written as,

$$
E_{z}^{(\operatorname{tr} 2)}\left(R_{3}^{\prime}\right)=\sum_{m=-\infty}^{\infty} G_{z m}^{(2)} \widetilde{J}_{z m} e^{j m \phi}=\sum_{m=-\infty}^{\infty} G_{z m}^{(2)}\left[\frac{1}{T_{\phi}} \int_{\phi^{\prime}} J_{z} e^{-j m \phi^{\prime}} d \phi^{\prime}\right] e^{j m \phi}
$$

where, $E_{z}^{(\operatorname{tr} 2)}\left(R_{3}^{\prime}\right)$ is determined from eqn. (3-a).

To solve the integral equation of (9). Galerkin's moment method is applied. To begin with, we first expand the unknown surface current density on the conducting strips $J_{Z}$ in terms of linear combinations of known basis functions as:

$\mathrm{J}_{\mathrm{Z}}\left(\phi^{\prime}\right)=\sum_{\mathrm{s}=1}^{\mathrm{P}} \sum_{\ell=0}^{\infty} \mathrm{a}_{\ell}^{(\mathrm{s})} \frac{\mathrm{T}_{\ell}\left(\mathrm{x}_{\mathrm{os}}^{\prime}\right)}{\sqrt{1-\left(\mathrm{x}_{\mathrm{os}}^{\prime}\right)^{2}}}\left[\mathrm{U}\left(\phi^{\prime}-\psi_{2 \mathrm{~s}}\right)-\mathrm{U}\left(\phi^{\prime}-\Psi_{2 \mathrm{~s}-1}\right)\right]$

where, $\mathrm{T}_{\ell}\left(\mathrm{x}_{\mathrm{os}}^{\prime}\right)$ is the Chebyshev polynomial of the first kind, $\mathrm{a}_{\ell}^{(\mathrm{s})}$ are the unknown expanding coefficients to be determined, $1 / \sqrt{1-\left(x_{\mathrm{OS}}^{\prime}\right)^{2}}$ is factor for edge effect of each aperture or strip and $x_{0 s}^{\prime}=\frac{\phi^{\prime}-\left(\Psi_{2 s}+\Psi_{2 s-1}\right) / 2}{\left(\Psi_{2 s}-\Psi_{2 s-1}\right) / 2}$.

Substitute by eqn. (10) into eqn. (9) gives: 


$$
\mathrm{E}_{\mathrm{z}}^{(\mathrm{tr} 2)}\left(\mathrm{R}_{3}^{\prime}\right)=\frac{1}{\mathrm{~T}_{\phi}} \sum_{\mathrm{m}=-\infty}^{\infty} \mathrm{G}_{\mathrm{zm}}^{(2)} \mathrm{e}^{\mathrm{jm} \phi} \sum_{\mathrm{s}=1}^{\mathrm{P}} \sum_{\ell=0}^{\infty} \mathrm{a}_{\ell}^{(\mathrm{s})} \int_{\phi^{\prime}} \frac{\mathrm{T}_{\ell}\left(\mathrm{x}_{\mathrm{os}}^{\prime}\right)}{\sqrt{1-\left(\mathrm{x}_{\mathrm{os}}^{\prime}\right)^{2}}} \mathrm{e}^{-\mathrm{jm} \phi^{\prime}} \mathrm{d} \phi^{\prime}
$$

\section{Numerical solution:}

Applying the Galerkin's procedure, both sides of eqn. (11) are multiplied by the factor $\mathrm{T}_{\mathrm{q}}\left(\mathrm{x}_{\mathrm{os}}\right) / \sqrt{1-\mathrm{x}_{\mathrm{os}}^{2}}, \mathrm{q}=0,1,2, \ldots \ldots, \infty$ for each strip $\left(\right.$ at $\left.\mathrm{x}_{\mathrm{os}}=\frac{\phi-\left(\Psi_{2 \mathrm{~s}}+\Psi_{2 \mathrm{~s}-1}\right) / 2}{\left(\Psi_{2 \mathrm{~s}}-\Psi_{2 \mathrm{~s}-1}\right) / 2}\right)$ and integrating over the region $\phi \in\left(\Psi_{2 s-1}, \Psi_{2 s}\right)$ respectively. Then,

$$
\begin{aligned}
& \int_{\phi}\left\{\sum_{\mathrm{s}=1 \mathrm{q}=0}^{\mathrm{P}} \sum_{\frac{\mathrm{q}}{1-\mathrm{x}_{\mathrm{os}}^{2}}}^{\infty} \mathrm{T}_{\mathrm{q}}\left(\mathrm{x}_{\mathrm{m}=-\infty}^{\infty} \mathrm{i}^{-\mathrm{m}}\left[\widetilde{\mathrm{A}}_{\mathrm{m}}^{(2)} \mathrm{H}_{\mathrm{m}}^{(2)}\left(\mathrm{K}_{2} \mathrm{R}_{3}^{\prime}\right)+\widetilde{\mathrm{B}}_{\mathrm{m}}^{(2)} \mathrm{J}_{\mathrm{m}}\left(\mathrm{K}_{2} \mathrm{R}_{3}^{\prime}\right)\right] \mathrm{e}^{\mathrm{jm}\left(\phi-\phi_{\text {in }}\right)}\right\} \mathrm{d} \phi\right.
\end{aligned}
$$

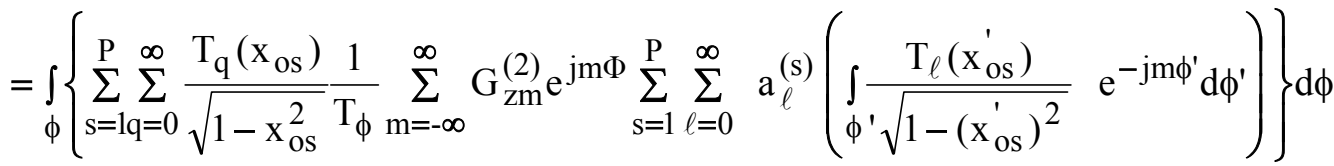

Thus, eqn. (12) can be written as,

$$
\begin{aligned}
\mathrm{E}_{\mathrm{o}} \sum_{\mathrm{m}=-\infty}^{\infty} \mathrm{i}^{-\mathrm{m}}\left[\widetilde{\mathrm{A}}_{\mathrm{m}}^{(2)} \mathrm{H}_{\mathrm{m}}^{(2)}\left(\mathrm{K}_{2} \mathrm{R}_{3}^{\prime}\right)+\widetilde{\mathrm{B}}_{\mathrm{m}}^{(2)} \mathrm{J}_{\mathrm{m}}\left(\mathrm{K}_{2} \mathrm{R}_{3}^{\prime}\right)\right] \mathrm{e}^{-\mathrm{jm} \phi_{\mathrm{in}}} \sum_{\mathrm{s}=1}^{\mathrm{P}} \sum_{\ell=0}^{\infty}\left(\mathrm{J}_{\mathrm{spt}}\right) \\
=\sum_{\mathrm{m}=-\infty}^{\infty} \mathrm{G}_{\mathrm{zm}}^{(2)} \sum_{\mathrm{s}=1}^{\mathrm{P}} \sum_{\ell=0}^{\infty} \mathrm{a}_{\ell}^{(\mathrm{s})}\left(\mathrm{J}_{\mathrm{spc}}\right)\left(\mathrm{J}_{\mathrm{spt}}\right)
\end{aligned}
$$

where,

$\mathrm{J}_{\mathrm{spc}} \ldots$ is the spectral amplitudes of the current basis function.

$$
\mathrm{J}_{\mathrm{spc}}=\frac{1}{\mathrm{~T}_{\phi}} \int_{\phi^{\prime}} \frac{\mathrm{T}_{\ell}\left(\mathrm{x}_{\mathrm{os}}^{\prime}\right)}{\sqrt{1-\left(\mathrm{x}_{\mathrm{os}}^{\prime}\right)^{2}}} \mathrm{e}^{-\mathrm{jm} \phi^{\prime}} \mathrm{d} \phi
$$

$\mathrm{J}_{\mathrm{spt}} \ldots$ is the spatial amplitudes of the current basis function.

$$
\mathrm{J}_{\mathrm{spt}}=\int_{\phi} \frac{\mathrm{T}_{\mathrm{q}}\left(\mathrm{x}_{\mathrm{os}}\right)}{\sqrt{1-\left(\mathrm{x}_{\mathrm{os}}\right)^{2}}} \mathrm{e}^{\mathrm{jm} \phi} \mathrm{d} \phi
$$

Equation. (13) can be represented in the matrix form as:

$$
[\mathrm{LHS}]_{(\mathrm{PxL}) \mathrm{x} 1}=[\mathrm{RHS}]_{(\mathrm{PxL}) \mathrm{x}(\mathrm{PxL})}[\mathrm{a}]_{(\mathrm{PxL}) \mathrm{x} 1}
$$

where, $\mathrm{L}$ is the number of induced current modes $(\ell, \mathrm{q}=0: \mathrm{L})$.

Thus, the current amplitude coefficients can be determined as:

$$
[\mathrm{a}]_{(\mathrm{PxL}) \mathrm{x} 1}=[\mathrm{RHS}]_{(\mathrm{PxL}) \mathrm{x}(\mathrm{PxL})}^{-1}[\mathrm{LHS}]_{(\mathrm{PxL}) \mathrm{x} 1}
$$




\section{Numerical results:}

Based on the above mathematical treatment, computer codes have been developed for calculating the penetrated (near-zone) field and scattered (far-zone) field components. Obviously, there is countless number of interesting cases that we can investigate where the field is function of many different factors such as operating frequency, geometrical dimensions and constitutive parameters of the coating layers, as well as the number of embedded conducting strips.

For the structure depicted in Fig. $1, \mathrm{R}_{1}=0.2 \mathrm{~m}, \mathrm{R}_{2}=0.25 \mathrm{~m}, \mathrm{R}_{3}^{\prime}=0.27 \mathrm{~m}$ and $\mathrm{R}_{3}=0.3 \mathrm{~m}$, while the constitutive parameters are $\varepsilon_{\mathrm{r} 1}=1.5, \varepsilon_{\mathrm{r} 2}=2.5$ and $\mu_{\mathrm{r} 1}=\mu_{\mathrm{r} 2}=1$. Consider the case of plane wave excitation with $\phi_{\text {in }}=90^{\circ}$ and its frequency $\mathrm{f}=100 \mathrm{MHz}$. The array geometries, embedded at $\mathrm{R}_{3}{ }_{3}$, have equal angular width of both the conductors and apertures. The array comprises one (half cylinder), two, four or six strips

At first, the validity of the formulated and written codes including the accuracy of the numerical solution has been fulfilled by computing the current and field distributions on surface containing the conducting strips. In order to achieve high accuracy in calculating the penetrated (near-zone) and scattered (far-zone) field components by Galerkin's procedure, the number of current modes $\mathrm{L}$ and field modes $\mathrm{M}(\mathrm{m}=-\mathrm{M}: \mathrm{M})$ should be chosen. According to numerical experiments and convergence study, 50 Chebyshev current modes $(\mathrm{L}=50)$ are employed for expanding the current, and $\mathrm{M}=35$ is used for the field modes.

Figure 2 shows the induced currents and field distributions on the cylindrical surface containing the conducting strips for the cases of one, two, four and six strips. It is clear that, there is a good symmetrical current distribution in the case of one strip-array, Fig.2(a), where the incident of the excitation plane wave is on the middle point of the strip, as the arrow indicated. Also, it shows that an accurate fulfillment of the boundary conditions was found on the surface of conducting strips in the four cases, where the summation of the scattered and incident fields equals zero.

Figure 3 depicts a three dimensional patterns of the penetrated (near-zone) field $\left(\mathrm{E}_{\mathrm{z}^{-}}\right.$ component) for the four cases of study. Fig. 3(a), the case of one strip, shows a considerable high level of the penetrated fields at the center of the cylindrical structure mainly due to the edge diffractions. Increasing the number of conducting strips while keeping the sum of the conductor size equals half the cylinder circumference, we can see that the penetrated field is gradually decreases. The case of six strips, in Fig. 3(d), exhibits a good shielding behavior where the field in the middle can be neglected (penetration ratio about $4.1074 \times 10^{-9}$ ). This result is further confirmed in the following by the far-zone scattered field.

Figure 4 shows the normalized amplitudes of scattered (far-zone) field for the same cases. The calculated results (the case of infinitely extended strips) are compared with the simulated one (strips with length 5 $\lambda$ ) using Zeland Fidelity Workshop (ZFW) and a good agreement was found. The difference between the calculated and simulated results comes from the edges of the finite length of the simulated cases. The figure also shows the simulation result for complete conducting cylinder, embedded at $\mathrm{R}_{3}^{\prime}$, as an ideal shielding case. We can see that, by increasing the number of embedded conducting strips, the results approach the ideal case. 


\section{Conclusion:}

In this paper, we have investigated the penetrated (near-zone) and the scattered (far-zone) fields characteristics of a TMz plane wave excitation of one, two, four and six infinitely extended conducting strip-arrays embedded in multilayer dielectric cylindrical structure. This technique, based on the Green's function combined with the Chebyshev polynomial with edge effect, is very flexible and efficient for such structures. Numerical results show that shielding performance is improved by increasing the number of conducting strips in the embedded array. Of course, similar procedure can be adopted for examining the field characteristics of a TEz plane wave excitation of infinitely extended conducting strip-array embedded in multilayer dielectric structure.

\section{References:}

[1] Senior, T. B. A., “ Electromagnetic field penetration into cylindrical cavity, ” IEEE Trans. Electromagn. Compat., vol. 1 EMC-18, pp 71-73, May 1976.

[2] J. R. Mautz and R. F. Harrington, " EM penetration into a conducting circular cylinder through narrow slot, TM case, ” J. Eletromag. Waves Appl., vol. 2, no. 3/4, pp. 269-293, 1988.

[3] J. R. Mautz and R. F. Harrington, EM penetration into a conducting circular cylinder through narrow slot, TE case, " J. Eletromag. Waves Appl., vol. 3, no. 4 , pp. 307336, 1989.

[4] R. F. Harrington and J. R. Mautz, “ A generalized network formulation for aperture problem,” IEEE Trans. Antenna propagate., vol. AP-24, pp. 870-873, Nov. 1976.

[5] J. D. Shumpert and C. M. Butler, "Penetration through slots in conducting cylinders - Part1: TE case,” IEEE Trans. Antenna propagate., vol. AP-46, pp. 1612-1621, Nov. 1998.

[6] J. D.Shumpert and C. M. Butler, "Penetration through slots in conducting cylinders Part2: TM case, ” IEEE Trans. Antenna propagate., vol. AP-46, pp. 1622-1628, Nov. 1998.

[7] W. Yin, L. Li, T. You, and M. Leong, “ Multiple penetration of a TEz - polarized plane wave into multilayered cylindrical cavity-backed apertures, " IEEE Trans. Antenna propagate., vol. AP-42, pp. 330-338, Nov. 2000.

[8] W. Yin, L. Li, T. Yeo, M. Leong and P. Kooi, “ The near-zone field characteristics of an E-polarization plane wave penetrating through cylindrical multiple apertures (non) coated with lossy and lossess media," IEEE Trans. Antenna propagate., vol. AP-44, pp. 329-337, May. 2002. 


\section{Appendix (A)}

In eqns. (2) - (5), the unknown coefficients are determined as:

$\widetilde{\mathrm{B}}_{\mathrm{m}}^{(\mathrm{in})}=\frac{\eta_{1} \mathrm{~N}}{\mathrm{~F}}\left\{\frac{\mathrm{H}^{\prime}\left(\mathrm{EQ}_{2}-\mathrm{C}\right)-\mathrm{FG}^{\prime} \mathrm{Q}_{2}-\mathrm{Q}_{4}\left[\mathrm{H}\left(\mathrm{EQ}_{2}-\mathrm{C}\right)-\mathrm{GFQ}_{2}\right]}{\eta_{1} \mathrm{Q}_{4}\left[\mathrm{~L}\left(\mathrm{P}-\mathrm{Q}_{3} \mathrm{M}\right)+\mathrm{NIQ}_{3}\right]-\eta_{2}\left[\mathrm{~L}^{\prime}\left(\mathrm{P}-\mathrm{Q}_{3} \mathrm{M}\right)+\mathrm{NI}^{\prime} \mathrm{Q}_{3}\right]}\right\}$

$\widetilde{\mathrm{A}}_{\mathrm{m}}^{(2)}=\frac{1}{\mathrm{~F}}\left[\widetilde{\mathrm{A}}_{\mathrm{m}}^{(0)}\left(\mathrm{D}-\mathrm{EQ}_{1}\right)-\mathrm{EQ}_{2}+\mathrm{C}\right]$

$\widetilde{\mathrm{B}}_{\mathrm{m}}^{(2)}=\widetilde{\mathrm{A}}_{\mathrm{m}}^{(0)} \mathrm{Q}_{1}+\mathrm{Q}_{2}$

$\widetilde{\mathrm{A}}_{\mathrm{m}}^{(1)}=\frac{1}{\mathrm{~N}} \widetilde{\mathrm{B}}_{\mathrm{m}}^{(\mathrm{in})}\left(\mathrm{P}-\mathrm{Q}_{3} \mathrm{M}\right)$

$\widetilde{\mathrm{A}}_{\mathrm{m}}^{\text {(out) }}=\frac{\mathrm{F}}{\mathrm{H}\left(\mathrm{D}-\mathrm{EQ}_{1}\right)+\mathrm{FGQ}_{1}}\left\{\widetilde{\mathrm{B}}_{\mathrm{m}}^{\text {(in })} \frac{\mathrm{L}\left(\mathrm{P}-\mathrm{Q}_{3} \mathrm{M}\right)+\mathrm{NIQ}_{3}}{\mathrm{~N}}+\frac{\mathrm{H}\left(\mathrm{EQ}_{2}-\mathrm{C}\right)-\mathrm{GFQ}_{2}}{\mathrm{~F}}\right\}$

where,
$\mathrm{Q}_{1}=\frac{\left(\eta_{2} \mathrm{D}^{\prime} \mathrm{F}-\eta_{\mathrm{o}} \mathrm{DF}^{\prime}\right)}{\eta_{\mathrm{o}}\left(\mathrm{E}^{\prime} \mathrm{F}-\mathrm{EF}^{\prime}\right)}$
$(\mathrm{A}-7) \quad, \quad \mathrm{Q}_{2}=\frac{\left(\eta_{2} \mathrm{C}^{\prime} \mathrm{F}-\eta_{\mathrm{o}} \mathrm{CF}^{\prime}\right)}{\eta_{\mathrm{o}}\left(\mathrm{E}^{\prime} \mathrm{F}-\mathrm{EF}^{\prime}\right)}$
$\mathrm{Q}_{3}=\frac{\left(\eta_{1} \mathrm{NP}^{\prime}-\eta_{\mathrm{o}} \mathrm{N}^{\prime} \mathrm{P}\right)}{\eta_{\mathrm{o}}\left(\mathrm{NM} \mathrm{M}^{\prime}-\mathrm{N}^{\prime} \mathrm{M}\right)}$
$\mathrm{Q}_{4}=\frac{\mathrm{H}^{\prime}\left(\mathrm{D}-\mathrm{EQ}_{1}\right)+\mathrm{G}^{\prime} \mathrm{FQ}_{1}}{\mathrm{H}^{\prime}\left(\mathrm{D}-\mathrm{EQ}_{1}\right)+\mathrm{G}^{\prime} \mathrm{FQ}_{1}}$

and,

$$
\left.\begin{array}{ll}
\mathrm{J}_{\mathrm{m}}\left(\mathrm{K}_{\mathrm{o}} \mathrm{R}_{3}\right)=\mathrm{C} & \mathrm{H}_{\mathrm{m}}^{(2)}\left(\mathrm{K}_{\mathrm{o}} \mathrm{R}_{3}\right)=\mathrm{D} \\
\mathrm{J}_{\mathrm{m}}^{\prime}\left(\mathrm{K}_{\mathrm{o}} \mathrm{R}_{3}\right)=\mathrm{C}^{\prime} & \mathrm{H}_{\mathrm{m}}^{(2)^{\prime}}\left(\mathrm{K}_{\mathrm{o}} \mathrm{R}_{3}\right)=\mathrm{D}^{\prime} \\
\mathrm{J}_{\mathrm{m}}\left(\mathrm{K}_{2} \mathrm{R}_{3}\right)=\mathrm{E} & \mathrm{H}_{\mathrm{m}}^{(2)}\left(\mathrm{K}_{2} \mathrm{R}_{3}\right)=\mathrm{F} \\
\mathrm{J}_{\mathrm{m}}^{\prime}\left(\mathrm{K}_{2} \mathrm{R}_{3}\right)=\mathrm{E}^{\prime} & \mathrm{H}_{\mathrm{m}}^{(2)^{\prime}}\left(\mathrm{K}_{2} \mathrm{R}_{3}\right)=\mathrm{F}^{\prime} \\
\mathrm{J}_{\mathrm{m}}\left(\mathrm{K}_{2} \mathrm{R}_{2}\right)=\mathrm{G} & \mathrm{H}_{\mathrm{m}}^{(2)}\left(\mathrm{K}_{2} \mathrm{R}_{2}\right)=\mathrm{H}^{\prime} \\
\mathrm{J}_{\mathrm{m}}^{\prime}\left(\mathrm{K}_{2} \mathrm{R}_{2}\right)=\mathrm{G}^{\prime} & \mathrm{H}_{\mathrm{m}}^{(2)^{\prime}}\left(\mathrm{K}_{2} \mathrm{R}_{2}\right)=\mathrm{H}^{\prime} \\
\mathrm{J}_{\mathrm{m}}\left(\mathrm{K}_{1} \mathrm{R}_{2}\right)=\mathrm{I} & \mathrm{H}_{\mathrm{m}}^{(2)}\left(\mathrm{K}_{1} \mathrm{R}_{2}\right)=\mathrm{L}^{\prime} \\
\mathrm{J}_{\mathrm{m}}^{\prime}\left(\mathrm{K}_{1} \mathrm{R}_{2}\right)=\mathrm{I}^{\prime} & \mathrm{H}_{\mathrm{m}}^{(2))^{\prime}}\left(\mathrm{K}_{1} \mathrm{R}_{2}\right)=\mathrm{L}^{\prime} \\
\mathrm{J}_{\mathrm{m}}\left(\mathrm{K}_{1} \mathrm{R}_{1}\right)=\mathrm{M} & \mathrm{H}_{\mathrm{m}}^{(2)}\left(\mathrm{K}_{1} \mathrm{R}_{1}\right)=\mathrm{N}^{\prime} \\
\mathrm{J}_{\mathrm{m}}^{\prime}\left(\mathrm{K}_{1} \mathrm{R}_{1}\right)=\mathrm{M}^{\prime} & \mathrm{H}_{\mathrm{m}}^{(2))^{\prime}}\left(\mathrm{K}_{1} \mathrm{R}_{1}\right)=\mathrm{N}^{\prime} \\
\mathrm{J}_{\mathrm{m}}\left(\mathrm{K}_{\mathrm{o}} \mathrm{R}_{1}\right)=\mathrm{P} & \\
\mathrm{J}_{\mathrm{m}}^{\prime}\left(\mathrm{K}_{\mathrm{o}} \mathrm{R}_{1}\right)=\mathrm{P}^{\prime} &
\end{array}\right\} \quad\left(\rho=\mathrm{R}_{2}\right)
$$

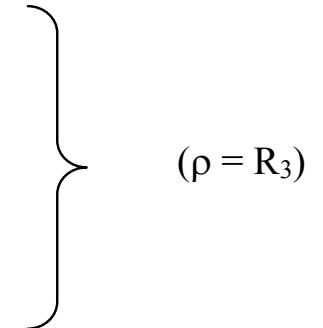




\section{Appendix (B)}

In eqn. (6) the unknown coefficients are determined as,

$$
\begin{aligned}
& \widetilde{\mathrm{B}}_{\mathrm{TMm}}^{\text {(out) }}=\chi_{7} \widetilde{\mathrm{J}}_{\mathrm{zm}}\left(\frac{\mathrm{K}_{2}}{\mathrm{j} \omega \varepsilon_{2}}\right) \\
& \widetilde{\mathrm{A}}_{\mathrm{TMm}}^{(\text {in })}=\left[\begin{array}{lll}
\chi_{3} & \mathrm{~L}_{1}+\chi_{4} & \mathrm{M}_{1} \\
\chi_{5} & \mathrm{~L}_{1}+\chi_{6} & \mathrm{M}_{1}
\end{array}\right] \widetilde{\mathrm{B}}_{\mathrm{TMm}}^{\text {(out) }} \\
& \widetilde{\mathrm{A}}_{\mathrm{TMm}}^{(1)}=\chi_{1} \widetilde{\mathrm{A}}_{\mathrm{TMm}}^{(\mathrm{in})} \\
& \text { (B-3) } \quad \widetilde{\mathrm{B}}_{\mathrm{TMm}}^{(1)}=\chi_{2} \widetilde{\mathrm{A}}_{\mathrm{TMm}}^{(\mathrm{in})} \\
& \widetilde{\mathrm{A}}_{\mathrm{TMm}}^{(2)}=\chi_{5} \widetilde{\mathrm{A}}_{\mathrm{TM}}^{(\mathrm{in})} \\
& \widetilde{\mathrm{B}}_{\mathrm{TMm}}^{(2)}=\chi_{6} \widetilde{\mathrm{A}}_{\mathrm{TMm}}^{(\mathrm{in})} \\
& \widetilde{\mathrm{A}}_{\mathrm{TMm}}^{(3)}=\chi_{3} \widetilde{\mathrm{B}}_{\mathrm{TMm}}^{\text {(out) }} \\
& \widetilde{\mathrm{B}}_{\mathrm{TMm}}^{(3)}=\chi_{4} \widetilde{\mathrm{B}}_{\mathrm{TMm}}^{\text {(out) }}
\end{aligned}
$$

where,

$$
\begin{aligned}
& \chi_{1}=\frac{\left(\varepsilon_{0} / \varepsilon_{1}\right)\left(\mathrm{K}_{1} / \mathrm{K}_{\mathrm{o}}\right) \mathrm{C}_{1}^{\prime} \mathrm{E}_{1}-\mathrm{C}_{1} \mathrm{E}_{1}^{\prime}}{\mathrm{E}_{1} \mathrm{D}_{1}^{\prime}-\mathrm{D}_{1} \mathrm{E}_{1}^{\prime}} \quad(\mathrm{B}-9) \quad \chi_{2}=\frac{\mathrm{C}_{1}-\chi_{1} \mathrm{D}_{1}}{\mathrm{E}_{1}} \\
& \chi_{3}=\left[\frac{\left(\mathrm{K}_{2} / \mathrm{K}_{\mathrm{o}}\right)\left(\varepsilon_{\mathrm{o}} / \varepsilon_{2}\right) \mathrm{O}_{1}^{\prime} \mathrm{P}_{1}-\mathrm{O}_{1} \mathrm{P}_{1}^{\prime}}{\mathrm{N}_{1}^{\prime} \mathrm{P}_{1}-\mathrm{N}_{1} \mathrm{P}_{1}^{\prime}}\right] \quad(\mathrm{B}-11) \quad \chi_{4}=\left[\frac{\left(\mathrm{O}_{1}-\chi_{3} \mathrm{~N}_{1}\right)}{\mathrm{P}_{1}}\right] \\
& \chi_{5}=\frac{\left(\mathrm{K}_{2} / \mathrm{K}_{1}\right)\left(\varepsilon_{1} / \varepsilon_{2}\right)\left(\chi_{1} \mathrm{~F}_{1}^{\prime}+\chi_{2} \mathrm{G}_{1}^{\prime}\right) \mathrm{I}_{1}-\left(\chi_{1} \mathrm{~F}_{1}+\chi_{2} \mathrm{G}_{1}\right) \mathrm{I}_{1}^{\prime}}{\left(\mathrm{H}_{1}^{\prime} \mathrm{I}_{1}-\mathrm{H}_{1} \mathrm{I}_{1}^{\prime}\right)} \\
& \chi_{6}=\left[\left(\chi_{1} \mathrm{~F}_{1}+\chi_{2} \mathrm{G}_{1}\right)-\chi_{5} \mathrm{H}_{1}\right] / \mathrm{I}_{1} \\
& \chi_{7}=\frac{\left(\chi_{5} \mathrm{~L}_{1}+\chi_{6} \mathrm{M}_{1}\right)}{\left(\chi_{5} \mathrm{~L}_{1}+\chi_{6} \mathrm{M}_{1}\right)\left(\chi_{3} \mathrm{~L}_{1}^{\prime}+\chi_{4} \mathrm{M}_{1}^{\prime}\right)-\left(\chi_{5} \mathrm{~L}_{1}^{\prime}+\chi_{6} \mathrm{M}_{1}^{\prime}\right)\left(\chi_{3} \mathrm{~L}_{1}+\chi_{4} \mathrm{M}_{1}\right)}
\end{aligned}
$$

and,

$$
\begin{aligned}
& \left.\begin{array}{lll}
\mathrm{J}_{\mathrm{m}}\left(\mathrm{K}_{\mathrm{o}} \mathrm{R}_{1}\right)=\mathrm{C}_{1} & \mathrm{~J}_{\mathrm{m}}\left(\mathrm{K}_{1} \mathrm{R}_{1}\right)=\mathrm{D}_{1} & \mathrm{H}_{\mathrm{m}}^{(2)}\left(\mathrm{K}_{1} \mathrm{R}_{1}\right)=\mathrm{E}_{1} \\
\mathrm{~J}_{\mathrm{m}}^{\prime}\left(\mathrm{K}_{\mathrm{o}} \mathrm{R}_{1}\right)=\mathrm{C}_{1}^{\prime} & \mathrm{J}_{\mathrm{m}}^{\prime}\left(\mathrm{K}_{1} \mathrm{R}_{1}\right)=\mathrm{D}_{1}^{\prime} & \mathrm{H}_{\mathrm{m}}^{(2)^{\prime}}\left(\mathrm{K}_{1} \mathrm{R}_{1}\right)=\mathrm{E}_{1}^{\prime}
\end{array}\right\} \quad\left(\rho=\mathrm{R}_{1}\right) \\
& \mathrm{J}_{\mathrm{m}}\left(\mathrm{K}_{1} \mathrm{R}_{2}\right)=\mathrm{F}_{1} \quad \mathrm{H}_{\mathrm{m}}^{(2)}\left(\mathrm{K}_{1} \mathrm{R}_{2}\right)=\mathrm{G}_{1} \\
& \mathrm{~J}_{\mathrm{m}}^{\prime}\left(\mathrm{K}_{1} \mathrm{R}_{2}\right)=\mathrm{F}_{1}^{\prime} \quad \mathrm{H}_{\mathrm{m}}^{(2)^{\prime}}\left(\mathrm{K}_{1} \mathrm{R}_{2}\right)=\mathrm{G}_{1}^{\prime} \\
& \mathrm{J}_{\mathrm{m}}\left(\mathrm{K}_{2} \mathrm{R}_{2}\right)=\mathrm{H}_{1}^{\prime} \quad \mathrm{H}_{\mathrm{m}}^{(2)}\left(\mathrm{K}_{2} \mathrm{R}_{2}\right)=\mathrm{I}_{1} \\
& \mathrm{~J}_{\mathrm{m}}^{\prime}\left(\mathrm{K}_{2} \mathrm{R}_{2}\right)=\mathrm{H}_{1}^{\prime} \quad \mathrm{H}_{\mathrm{m}}^{(2)^{\prime}}\left(\mathrm{K}_{2} \mathrm{R}_{2}\right)=\mathrm{I}_{1}^{\prime} \\
& \left.\begin{array}{ll}
J_{m}\left(K_{2} R_{3}^{\prime}\right)=L_{1} & H_{m}^{(2)}\left(K_{2} R_{3}^{\prime}\right)=M_{1} \\
J_{m}^{\prime}\left(K_{2} R_{3}^{\prime}\right)=L_{1}^{\prime} & H_{m}^{(2){ }^{\prime}}\left(K_{2} R_{3}^{\prime}\right)=M_{1}^{\prime}
\end{array}\right\} \quad\left(\rho=R_{3}^{\prime}\right) \\
& \left.\begin{array}{lll}
\mathrm{J}_{\mathrm{m}}\left(\mathrm{K}_{2} \mathrm{R}_{3}\right)=\mathrm{N}_{1} & \mathrm{H}_{\mathrm{m}}^{(2)}\left(\mathrm{K}_{2} \mathrm{R}_{3}\right)=\mathrm{P}_{1} & \mathrm{H}_{\mathrm{m}}^{(2)}\left(\mathrm{K}_{\mathrm{o}} \mathrm{R}_{3}\right)=\mathrm{O}_{1} \\
\mathrm{~J}_{\mathrm{m}}^{\prime}\left(\mathrm{K}_{2} \mathrm{R}_{3}\right)=\mathrm{N}_{1}^{\prime} & \mathrm{H}_{\mathrm{m}}^{(2){ }^{\prime}}\left(\mathrm{K}_{2} \mathrm{R}_{3}\right)=\mathrm{P}_{1}^{\prime} & \mathrm{H}_{\mathrm{m}}^{(2)}\left(\mathrm{K}_{2} \mathrm{R}_{3}\right)=\mathrm{O}_{1}^{\prime}
\end{array}\right\} \quad\left(\rho=\mathrm{R}_{3}\right)
\end{aligned}
$$




\section{Appendix (C)}

The variables $\mathrm{V}_{1}, \mathrm{~V}_{2}, \mathrm{~V}_{3}, \mathrm{~V}_{4}, \mathrm{~V}_{5}, \mathrm{~V}_{6}, \mathrm{~V}_{7}$ and $\mathrm{V}_{8}$ in eqn. (8) are determined as,

$$
\begin{aligned}
& \mathrm{V}_{1}=\frac{\left(\varepsilon_{\mathrm{o}} / \varepsilon_{1}\right)\left(\mathrm{K}_{1} / \mathrm{K}_{\mathrm{o}}\right) \mathrm{C}_{1}^{\prime} \mathrm{E}_{1}-\mathrm{C}_{1} \mathrm{E}_{1}^{\prime}}{\mathrm{E}_{1} \mathrm{D}_{1}^{\prime}-\mathrm{D}_{1}^{\prime} \mathrm{E}_{1}^{\prime}} \quad(\mathrm{C}-1), \quad \mathrm{V}_{2}=\frac{\mathrm{C}_{1}-\mathrm{V}_{1} \mathrm{D}_{1}}{\mathrm{E}_{1}} \\
& \mathrm{~V}_{3}=\left[\frac{\left(\mathrm{K}_{2} / \mathrm{K}_{\mathrm{o}}\right)\left(\varepsilon_{\mathrm{o}} / \varepsilon_{2}\right) \mathrm{O}_{1}^{\prime} \mathrm{P}_{1}-\mathrm{O}_{1} \mathrm{P}_{1}^{\prime}}{\mathrm{N}_{1}^{\prime} \mathrm{P}_{1}-\mathrm{N}_{1} \mathrm{P}_{1}^{\prime}}\right] \quad(\mathrm{C}-3), \quad \mathrm{V}_{4}=\left[\frac{\left(\mathrm{O}_{1}-\mathrm{V}_{3} \mathrm{~N}_{1}\right)}{\mathrm{P}_{1}}\right] \\
& \mathrm{V}_{5}=\frac{\left(\mathrm{K}_{2} / \mathrm{K}_{1}\right)\left(\varepsilon_{1} / \varepsilon_{2}\right)\left(\mathrm{V}_{1} \mathrm{~F}_{1}^{\prime}+\mathrm{V}_{2} \mathrm{G}^{\prime}\right) \mathrm{I}_{1}-\left(\mathrm{V}_{1} \mathrm{~F}_{1}+\mathrm{V}_{2} \mathrm{G}_{1}\right) \mathrm{I}_{1}^{\prime}}{\left(\mathrm{H}_{1}^{\prime} \mathrm{I}_{1}-\mathrm{H}_{1} \mathrm{I}_{1}^{\prime}\right)} \\
& \mathrm{V}_{6}=\frac{\left(\mathrm{V}_{1} \mathrm{~F}_{1}+\mathrm{V}_{2} \mathrm{G}_{1}\right)-\mathrm{V}_{5} \mathrm{H}_{1}}{\mathrm{I}_{1}} \\
& \mathrm{~V}_{7}=\frac{\left(\mathrm{V}_{5} \mathrm{~L}_{1}+\mathrm{V}_{6} \mathrm{M}_{1}\right)}{\left(\mathrm{V}_{5} \mathrm{~L}_{1}+\mathrm{V}_{6} \mathrm{M}_{1}\right)\left(\mathrm{V}_{3} \mathrm{~L}_{1}^{\prime}+\mathrm{V}_{4} \mathrm{M}_{1}^{\prime}\right)-\left(\mathrm{V}_{5} \mathrm{~L}_{1}^{\prime}+\mathrm{V}_{6} \mathrm{M}_{1}^{\prime}\right)\left(\mathrm{V}_{3} \mathrm{~L}_{1}+\mathrm{V}_{4} \mathrm{M}_{1}\right)} \\
& \mathrm{V}_{8}=\left[\begin{array}{lll}
\mathrm{V}_{3} & \mathrm{~L}+\mathrm{V}_{4} & \mathrm{M} \\
\hline \mathrm{V}_{5} & \mathrm{~L}+\mathrm{V}_{6} & \mathrm{M}
\end{array}\right]
\end{aligned}
$$

where,

$\mathrm{C}_{1}, \mathrm{C}_{1}^{\prime}, \mathrm{D}_{1}, \mathrm{D}_{1}^{\prime}, \mathrm{E}_{1}, \mathrm{E}_{1}^{\prime}, \mathrm{F}_{1}, \mathrm{~F}_{1}^{\prime}, \mathrm{G}_{1}, \mathrm{G}_{1}^{\prime}, \mathrm{H}_{1}, \mathrm{H}_{1}^{\prime}, \mathrm{I}_{1}, \mathrm{I}_{1}^{\prime}, \mathrm{L}_{1}, \mathrm{~L}_{1}^{\prime}, \mathrm{M}_{1}, \mathrm{M}_{1}^{\prime}, \mathrm{N}_{1}, \mathrm{~N}_{1}^{\prime}, \mathrm{P}_{1}, \mathrm{P}_{1}^{\prime}, \mathrm{O}_{1}$ and $\mathrm{O}_{1}^{\prime}$ are all given in appendix $(\mathrm{B})$. 

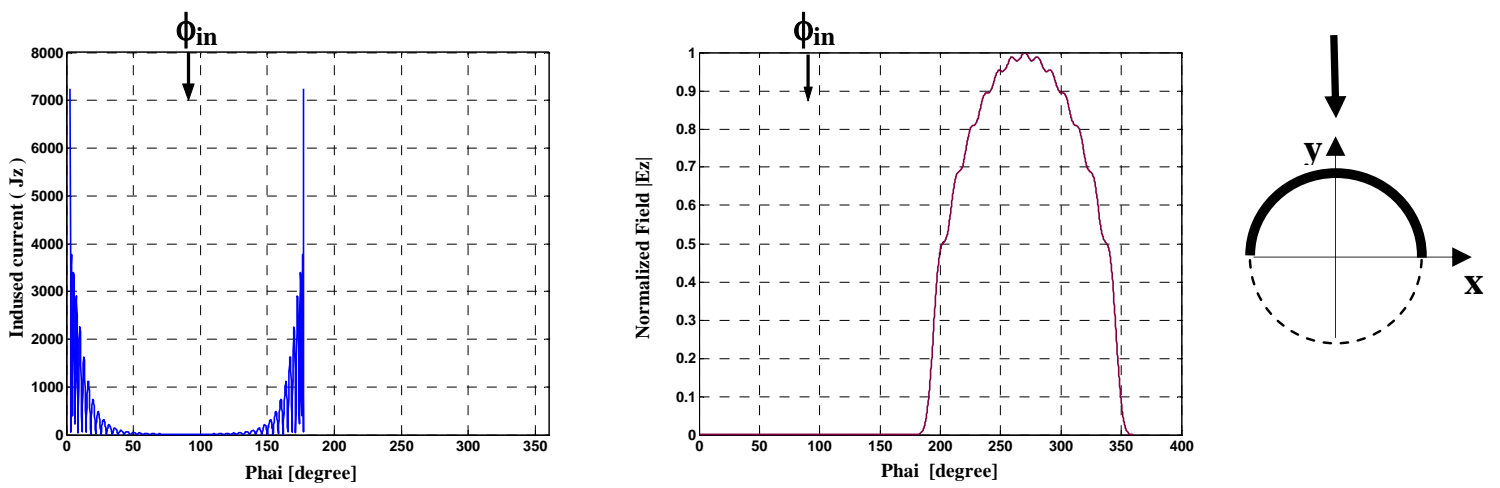

(a) One strip.
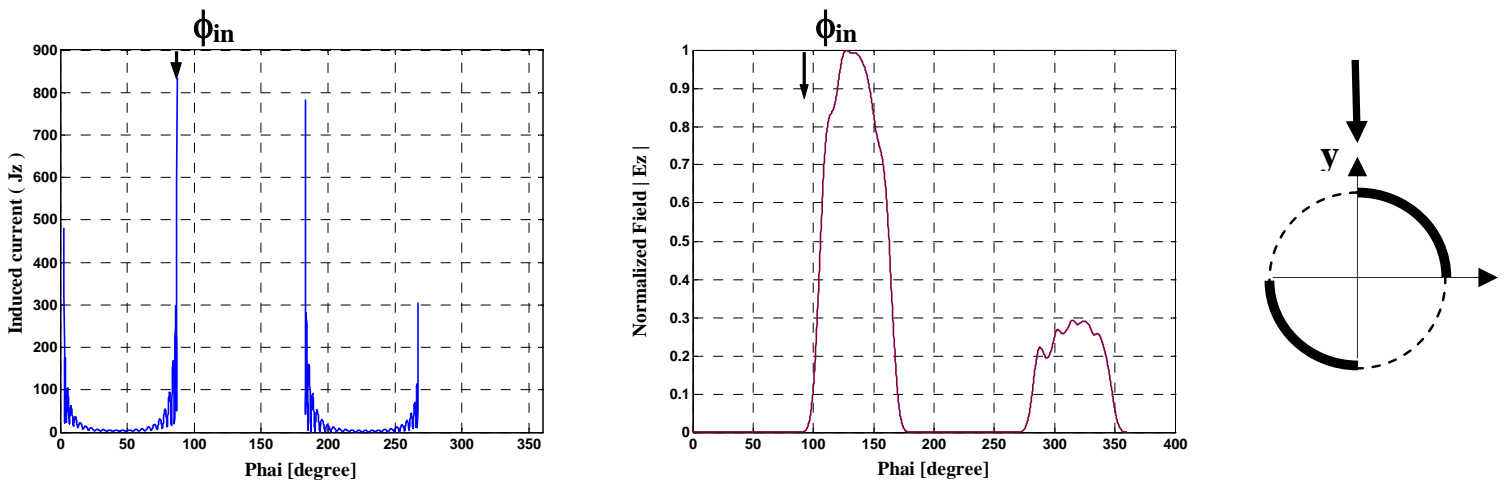

(b) Two strips.
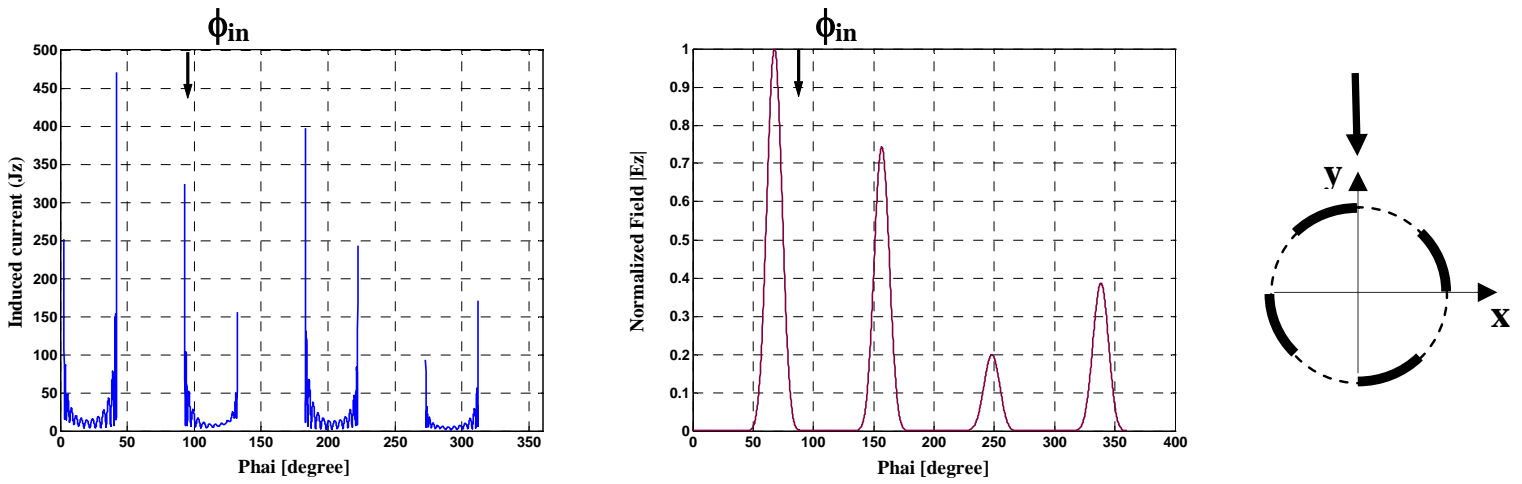

(c) Four strip
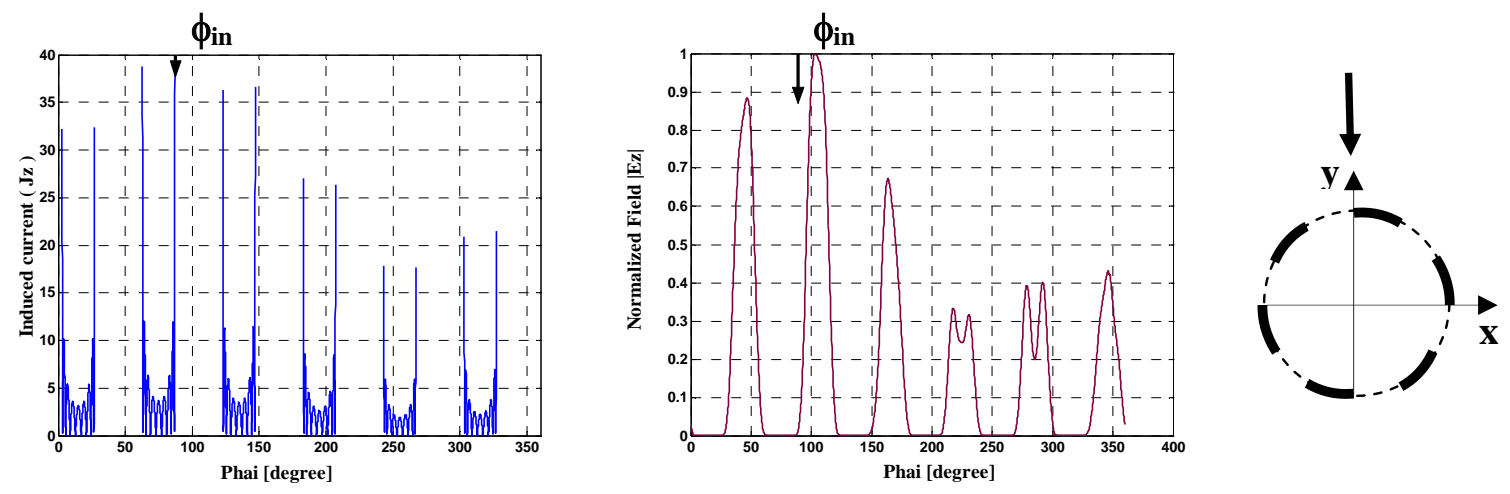

(d) Six strips.

Fig. 2 The magnitude of the induced current $\left(\mathrm{J}_{\mathrm{z}}\right)$ and the aperture field distribution $\left|\mathrm{E}_{\mathrm{z}}\right|$ for the cases of (a) one strip, (b) two strips, (c) four strips and (d) six strips. 


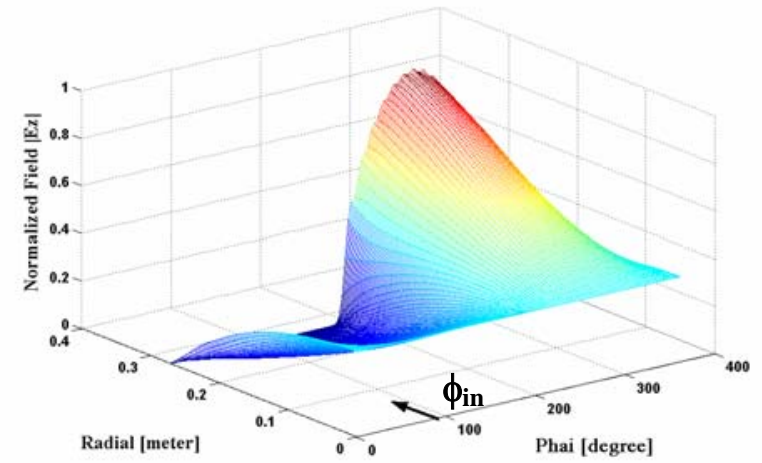

(a) One strip.

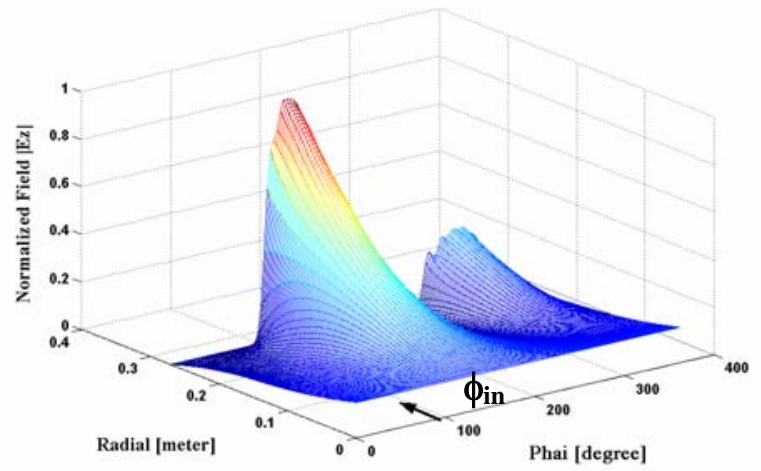

(b) Two strips.

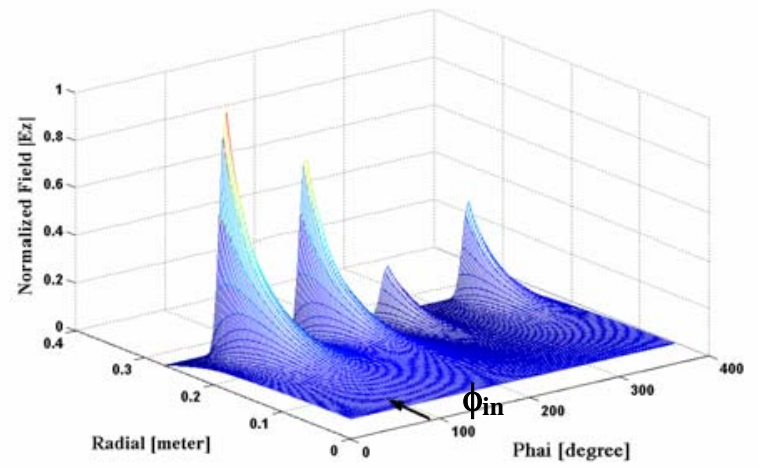

(c) Four Strips.

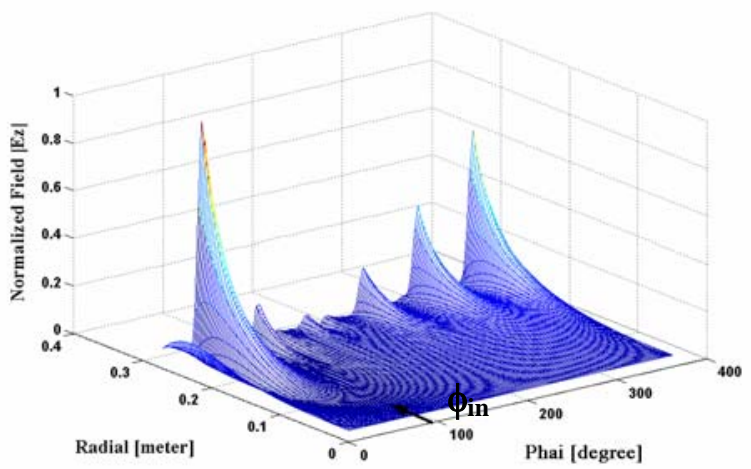

(d) Six strips.

Fig. 3 The penetrated (near-zone) field for the cases of (a) one strip, (b) two strips, (c) four strips and (d) six strips. 


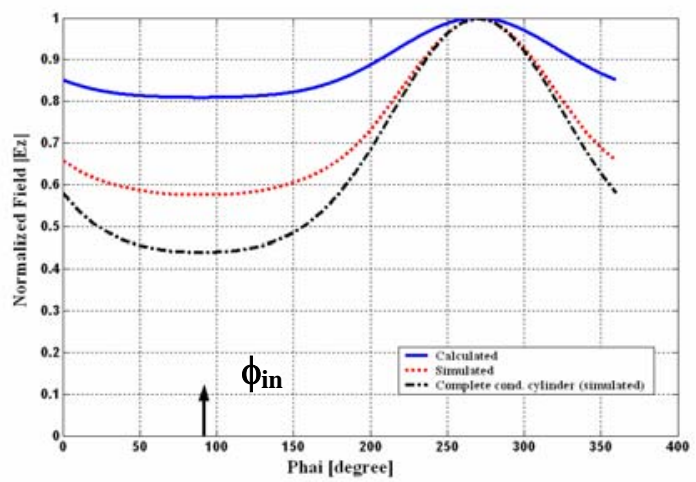

(a) One strip.

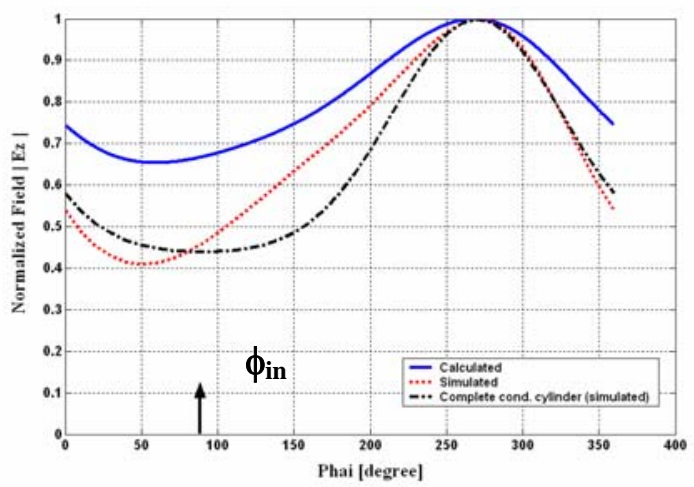

(b) Two strips.

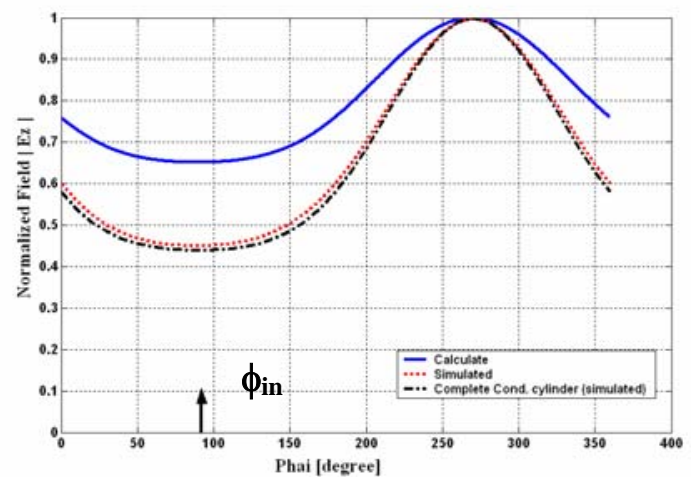

(c) Four strips.

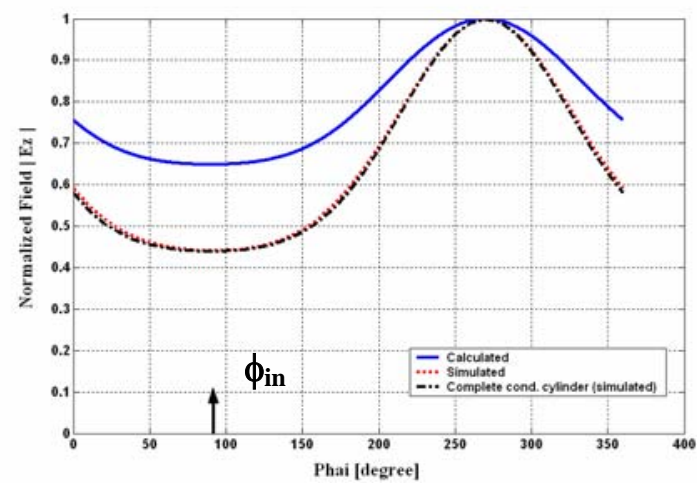

(d) Six strips.

Fig. 4 The scattered (far-zone) field for the cases of (a) one strip, (b) two strips, (c) four strips and (d) six strips. 